\title{
THE LINK BETWEEN LEADERSHIP STYLES AND BARRIERS TO ENTREPRENEURSHIP AMONG WOMEN
}

\author{
Bahaudin G. Mujtaba, Nova Southeastern University, U.S.A. \\ Ravi Chinta, Nova Southeastern University, U.S.A. \\ Belay Seyoum, Nova Southeastern University, U.S.A.
}

dx.doi.org/10.18374/JABE-20-1.3

\begin{abstract}
The workforce has become more diverse than ever in the past. However, despite the excellent progress toward inclusion based on gender and other dimensions of diversity, inequalities and disparities seem to exist among men and women entrepreneurs. In this study, based on the survey of 1246 current and aspiring American entrepreneurs, we attempt to understand the relationship of such demographic variables as ethnicity, education, gender, and being open-minded with leadership styles of aspiring female entrepreneurs while investigating success factors based on necessity and opportunity-driven entrepreneurship. The results demonstrate the college educated and female entrepreneurs are more relationship-oriented, while male respondents are more task-oriented. The findings show that the college-educated entrepreneurs are more likely to be driven toward entrepreneurship based on available opportunities. Our analysis provided further evidence that high self-efficacy and being open-minded are significant factors in becoming an entrepreneur. Based on the foundlings of this study, we provide suggestions and recommendations for equality of opportunity for current and future female entrepreneurs.
\end{abstract}

Keywords: Opportunity-Driven Entrepreneurship; Necessity-Driven Entrepreneurship; Being Open-Minded; Leadership Styles; Task Orientation; Relationship Orientation. 